\title{
Erratum to: EG-VEGF Maintenance Over Early Gestation to Develop a Pregnancy-Induced Hypertensive Animal Model
}

\author{
Déborah Reynaud, Frédéric Sergent, Roland Abi Nahed, \\ Sophie Brouillet, Mohamed Benharouga, and Nadia Alfaidy
}

\section{Erratum to:}

Chapter 25 in: Padma Murthi and Cathy Vaillancourt (eds.), Preeclampsia:

Methods and Protocols, Methods in Molecular Biology, vol. 1710 https://doi.org/10.1007/978-1-4939-7498-6_25

The information of the co-author of Chapter 25 (EG-VEGF Maintenance Over Early Gestation to Develop a Pregnancy-Induced Hypertensive Animal Model) Roland Abi Nahed was incorrectly indexed as Nahed RA instead of Abi Nahed R.

We have updated the author name with the correct information. 